\title{
A novel method of modifying immune responses by vaccination with lipiodol-siRNA mixtures
}

\author{
Thomas E Ichim*†1, Igor A Popov ${ }^{\dagger 2}$, Neil H Riordan¹, Hamid Izadi, \\ Zaohui Zhong ${ }^{3}$, Li Yijian ${ }^{3}$, Salman Sher ${ }^{4}$ and Eugenia K Oleinik ${ }^{5}$
}

\author{
Address: ${ }^{1}$ Medistem Laboratories Inc, Tempe Arizona, USA, ${ }^{2}$ Department of Surgery, University of Western Ontario, London, Ontario, Canada, \\ ${ }^{3}$ The Second Xiangya Hospital of Central South University, Changsha, China, ${ }^{4}$ Division of Cardiology, Emory University, Atlanta, USA and \\ ${ }^{5}$ Institute of Biology, Karelian Research Center, Russian Academy of Sciences, Petrozavodsk, Russia \\ Email: Thomas E Ichim* - thomas.ichim@gmail.com; Igor A Popov - ipopov@uwo.ca; Neil H Riordan - nhriordan@yahoo.com; \\ Hamid Izadi - gavrored@hotmail.com; Zaohui Zhong - zhaohui_zhong@yahoo.com; Li Yijian - lyj202aa@yahoo.com.cn; \\ Salman Sher - ssher2@emory.edu; Eugenia K Oleinik - ole@krc.karelia.ru \\ * Corresponding author †Equal contributors
}

Published: 03 January 2006

Journal of Translational Medicine 2006, 4:2 doi:10.1 186/1479-5876-4-2
Received: 21 October 2005

Accepted: 03 January 2006

This article is available from: http://www.translational-medicine.com/content/4/I/2

(C) 2006 Ichim et al; licensee BioMed Central Ltd.

This is an Open Access article distributed under the terms of the Creative Commons Attribution License (http://creativecommons.org/licenses/by/2.0), which permits unrestricted use, distribution, and reproduction in any medium, provided the original work is properly cited.

\begin{abstract}
The dendritic cell (DC) possesses the ability to stimulate both T helper I (ThI) and Th2 responses depending on activation stimuli. Although it is known that chemically or genetically modified DC can be used therapeutically to steer immune responses towards either ThI or Th2, cellular therapy with ex vivo manipulated DC is clinically difficult. Here we demonstrate a novel method of switching immune responses from Thl to Th2 through in vivo immune modulation by administration of siRNA. We demonstrate that siRNA targeting of the IL-I2p35 gene leads to a Th2 bias in vitro through an IL- 10 dependent mechanism. In vivo administration of siRNA admixed with the oil-based contrast agent lipiodol in the presence of antigen and adjuvant induced a deviation in recall response to reduced production of IFN- $\gamma$ and augmented IL-4 response using either KLH or ovalbumin. This simple method of in vivo modification of immune response possesses therapeutic potential in ThI-mediated diseases such as multiple sclerosis and autoimmune diabetes.
\end{abstract}

\section{Introduction}

It is known that the immune response can be polarized into two broad subsets based on cytokine secretion of the T helper cells. T helper-1 cells (Th1) responses are associated with anti-viral and anti-cancer immune reactions and are characterized by high secretion of the cytokine IFN- $\gamma$ and IL-2 [1]. In contrast, Th2 responses are effective for clearing parasitic infections such as schistosoma mansoni and are identified by high secretion of IL-4 and IL-13 [2]. In various human diseases a pathological polarization of the immune responses either to Th1 or Th2 is known to occur. For example, autoimmune diseases such as diabe- tes [3], multiple sclerosis [4], or arthritis [5], are associated with overproduction of Th1 cytokines. The causative role of these cytokines is noted by amelioration of animal models of autoimmune disease through treatment with inhibitors of such cytokines, such as antibodies or soluble receptors; however, clinical utilization is often impeded by systemic, non-desired side effects. Therefore a desired method of treating autoimmune diseases associated with Th1-hyperactivities would be targeting the actual initiating event that triggers such immune reactions. 
It is known that naïve CD4+ $\mathrm{T}$ helper cells (Th0) are programmed by the antigen presenting cell in order to become polarized into either the Th1 or Th2 phenotype [6]. More recent studies have demonstrated that dendritic cells (DC) play a key role in recognizing the exogenous pathogens, and making the decision of whether a Th1 or Th2 response is needed [7]. For example, parasites contain distinct chemical signatures that are recognized by specialized toll-like receptors (TLR) on DC, which instruct the DC to promote the appropriate response. In the case of schistosomiasis, the schistosomal egg antigen (SEA) is known to bind to TLR-2 on DC, and stimulate production of IL-13, which in turn shifts the Th0 cell into a Th2 cells $[8,9]$. Conversely, Gram-negative bacteria contain lipopolysaccaride (LPS), which activates TLR-4, leading to production of IL- 12 by the DC, which then stimulates Th1 differentiation [10]. Since it is established that Th1 immunity is essential for clearance of many Gram-negative bacteria, it appears that the DC plays a "central cognitive" role in guiding the immune response. Conversely, manipulation of this cell type would allow us to selectively modulate immune responses to either Th1 or Th2. Since DC can be pulsed with antigen, the manipulation of antigenpulsed DC would allow for selective alterations of immunity in an antigen-specific manner. Although this has been performed in animal models of autoimmunity [1115], the clinical utilization is hampered by the need for ex vivo cellular manipulation, which is expensive and difficult.

RNA interference (RNAi) is the cellular defense mechanism by which a double-stranded RNA specifically silences mRNA transcripts with strict homology to the double strand [16]. The silencing effect of exogenous double-stranded RNA is very potent in that it can mediate gene-silencing even at a concentration of 1-3 double strands per cell [17]. In light of this potency and selectivity, the induction of RNAi in DC would allow for silencing of genes that stimulate either Th1 or Th2. Since it is known that inhibition of Th1 cytokines in DC results in the stimulation of Th2 immunity and vice versa, we hypothesize that silencing of IL-12 would result in DC with a propensity of stimulating Th2 immune responses.

While we and others have been able to modify immunological parameters of DC through silencing IL-10 [18], IL12p35 [19], IL-12p40 [20], T-bet [21] and SOCS1 [22], a method of easily inducing immune modulation in vivo is lacking. In this study we induce an "in vivo genetic modification", presumably through DC using an immobilizing agent (CFA), a transfection associated agent (lipidiol) and antigen. We demonstrate inhibition of Th1 and upregulation of Th2 responses using this simple immunization protocol.

\section{Materials and methods Animals}

Female C57/BL6 and BALB/c mice (The Jackson Laboratories, Bar Harbor, ME), 5 wk of age, were kept in filter-top cages at the Animal Care and Veterinary Services Facility, the University of Western Ontario according to the Canadian Council for Animal Care Guidelines. Mice were fed by food and water ad libitum and allowed to settle for 2 wk before initiation of experimentations.

\section{DC generation and siRNA transfection}

At Day 0, bone marrow cells were flushed from the femurs and tibias of C57/BL6 mice, washed and cultured in 6well plates (Corning, NY) at $4 \times 10^{6}$ cells/well in $4 \mathrm{ml}$ of complete medium (RPMI 1640 supplemented with $2 \mathrm{mM}$ L-glutamine, $100 \mathrm{U} / \mathrm{ml}$ penicillin, $100 \mu \mathrm{g}$ of streptomycin, $50 \mu \mathrm{M}$ 2-ME, and 10\% FCS (all from Life Technologies, Ontario, Canada) supplemented with recombinant GM-CSF (10 ng/ml; PeproTech, Rocky Hill, NJ) and recombinant mouse IL-4 $(10 \mathrm{ng} / \mathrm{ml}$; PeproTech). All cultures were incubated at $37^{\circ} \mathrm{C}$ in $5 \%$ humidified $\mathrm{CO}_{2}$. Non-adherent cells were removed after $48 \mathrm{~h}$ of culture (Day 2) and fresh medium was added. After 7 days of culture, $>90 \%$ of the cells expressed the characteristic DCspecific marker CD11c as determined by FACS. DC were washed and plated in 24-well plates at a concentration of $2 \times 10^{5}$ cells/well in $400 \mu \mathrm{l}$ of serum-free RPMI 1640 . Transfection with GenePorter, lipiodol, or naked siRNA was performed as described below on day 7 of culture.

\section{siRNA synthesis and transfection}

siRNA sequences were selected according to the method previously used by us [19]. siRNA specific for IL-12p35 (AACCUGCUGAAGACCACAGAU) or mismatched (mixed) control sequence (AACTGCCAGATGGATGGTGAC) were synthesized and annealed by the manufacturer (Dharmacon, Lafayette, CO) and added at a concentration of $60 \mathrm{pMol}$ to DC cultures. For transfection, $3 \mu \mathrm{l}$ of 20 $\mu \mathrm{M}$ annealed siRNA were incubated with $3 \mu \mathrm{l}$ of GenePorter (Gene Therapy Systems, San Diego, CA) or lipiodol (Ultra-Fluide ${ }^{\mathrm{TM}}$ Laboratoire Guerbet, France) in a volume of $100 \mu \mathrm{l}$ of RPMI 1640 (serum free) at room temperature for $30 \mathrm{~min}$. This was then added to $400 \mu \mathrm{l}$ of DC cell culture as described above. Mock controls were transfected with $3 \mu \mathrm{l}$ of GenePorter alone. For naked siRNA, addition of the same concentration of siRNA was performed and procedures were repeated in an identical manner with the exception of addition of transfection reagent. After $4 \mathrm{~h}$ of incubation, an equal volume of RPMI 1640 supplemented with $20 \%$ FCS was added to the cells. Twenty-four hours later, transfected DC were washed and used for subsequent experiments. DC activation was performed in 24well plates by stimulation with LPS $(10 \mathrm{ng} / \mathrm{ml}$; SigmaAldrich, St. Louis, MO) plus TNF- (10 ng/ml; PeproTech) for 24 hours. 


\section{Flow cytometry}

Phenotypic analysis of DC was performed using flow cytometry on a FACScan (Becton Dickninson, San Jose, CA) and analyzed using CellQuest software (BD Biosciences). The cells were stained with FITC-conjugated mAb against surface markers associated with DC maturation: anti-mouse CD11c, anti-mouse CD40, anti-mouse CD80, and anti-mouse CD86 (Cedarlane Laboratories, Mississauga, ON). Ig of the same isotype were used as controls. Annexin $\mathrm{V}$ and propidium iodine analysis for apoptosis, necrosis was performed using the Apotag kit (Cedarlane Laboratories, Hornby Ontario, Canada).

\section{Mixed lymphocyte reaction}

C57/BL6 DC after transfection were irradiated (3,000 rad) and seeded in triplicate at various concentrations in a flatbottom 96-well plate (Corning) for use as stimulator cells. Splenic T cells from BALB/c mice were isolated by gradient centrifugation over Ficoll-Paque (Amersham Pharmacia Biotech, Quebec) and T cell nylon wool column purification, and added as responders $\left(5 \times 10^{5}\right.$ cells/well). The mixed lymphocytes were cultured at $37^{\circ} \mathrm{C}$ for $72 \mathrm{~h}$ in 200 $\mu \mathrm{l}$ of RPMI 1640 supplemented with 10\% FCS, $100 \mathrm{U} / \mathrm{ml}$ of penicillin, and $100 \mu \mathrm{g} / \mathrm{ml}$ of streptomycin and pulsed with $1 \mu \mathrm{Ci}$ /well of ${ }^{3} \mathrm{H}$-labelled thymidine (Amersham Pharmacia Biotech) for the last $16 \mathrm{~h}$ of culture. Cells were harvested onto glass fiber filters, and the radioactivity incorporated was quatitated using a Wallac Betaplate liquid scintillation counter (Beckman, Fullerton, CA). Results were expressed as the mean counts per min of triplicate cultures \pm SEM. In some experiments anti-IL-10 (JES5 2A5, Pharmingen) or isotype control antibody were added for the duration of the MLR at a concentration of 5 $\mathrm{ug} / \mathrm{ml}$.

\section{Immunization with Ag/Lipiodol mixture}

C57/BL6 mice were immunized intradermally at the interior side of both hind legs with $100 \mu \mathrm{l}$ of KLH or ovalbu$\min (1 \mu \mathrm{g} / \mu \mathrm{l})$ emulsified in CFA (Difco Laboratories, Detroit, MI) in the presence or absence of $10 \mathrm{nMol}$ siRNA and $10 \%$ lipiodol. After 14 days mice were sacrificed and T cells extracted as described above.

\section{Proliferation assays}

Proliferative recall responses to KLH and ovalbumin in immunized mice were assessed by sacrificing C57/BL6 mice 14 days after immunization with antigen-loaded DC. T cells were purified from suspensions of lymph nodes using CD4+ T cell column (R\&D Systems) after washing in PBS. Purified T cells were cultured in 96 well plates with irradiated syngeneic splenocytes in triplicate and mixed with serial dilutions of KLH or OVA at concentrations ranging from $0-10 \mathrm{ug} / \mathrm{ml}$. Following a $72-\mathrm{h}$ incubation, $1 \mu \mathrm{Ci}$ of $\left[{ }^{3} \mathrm{H}\right]$ thymidine (Amersham) was added to each well for $16 \mathrm{~h}$. Using an automated cell harvester, the

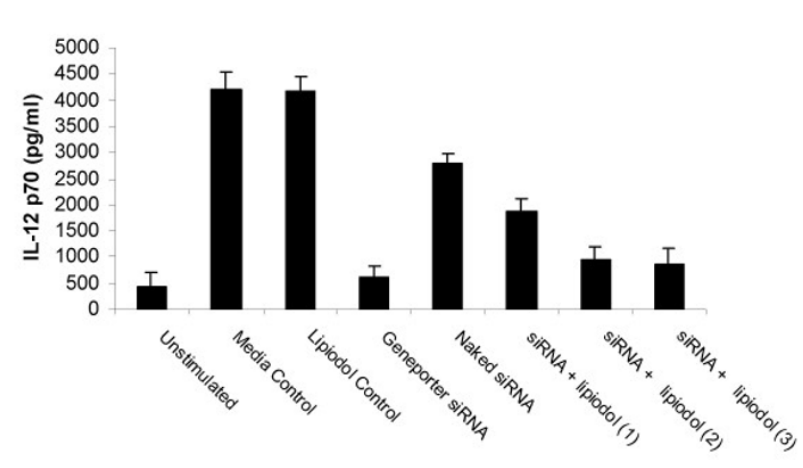

\section{Figure I}

Lipiodol can serve as a transfection reagent. Day 7 bone marrow derived DC were cultured alone, or with IL- I 2 p35 specific siRNA delivered by optimized GenePorter concentration ( $3 \mu \mathrm{l} /$ culture) or 3 concentrations of lipiodol (I,2, or $3 \mu \mathrm{l} /$ culture). Following a 24 hour incubation cells were plated at $1 \times 10^{6}$ in 6 well culture dishes and activated for 24 hours with $10 \mathrm{ng} / \mathrm{ml}$ LPS and $10 \mathrm{ng} / \mathrm{ml}$ TNF- $\alpha$. Supernatant was harvested and analyzed by ELISA for IL- 12 p70 production.

cells were collected onto glass microfiber filter, and the radioactive labeling incorporation was measured by a Wallac Betaplate liquid scintillation counter.

\section{ELISA}

The supernatants from recall response $\mathrm{T}$ cell cultures or MLR were harvested and assessed for DC cytokines (IL12p70, IL-10) and T cell cytokines (IFN-, IL-4) by ELISA. Cytokine-specific ELISA (Endogen, Rockford, IL) was used for detecting cytokine concentrations in culture supernatants according to the manufacturer's instructions using a Benchmark Microplate Reader (Bio-Rad, Hercules, CA).

\section{Results \\ Lipiodol enhances transfection of functional siRNA into DC}

We have previously demonstrated that transfection of DC with siRNA specific for the p35 component of IL-12 induces potent gene specific silencing at the mRNA transcript level as demonstrated by RT-PCR and subsequently reduced expression of the IL-12 p70 heterodimer as witnessed by ELISA protein [19]. Furthermore, we and others have reported that siRNA can be endocytosed into dendritic cells (DC) and other cell types in absence of transfection reagent both in vitro and in vivo [23-25]. Since lipiodol is a clinically used contrast agent with ability to mediate transfection of siRNA[26] in vivo, we chose to investigate whether lipiodol can be used to increase uptake of siRNA in DC in using an in vitro system.

In our laboratory, the combination of $10 \mathrm{ng} / \mathrm{ml}$ of LPS and TNF- $\alpha$, respectively, (LPS/TNF) is used as a standard 

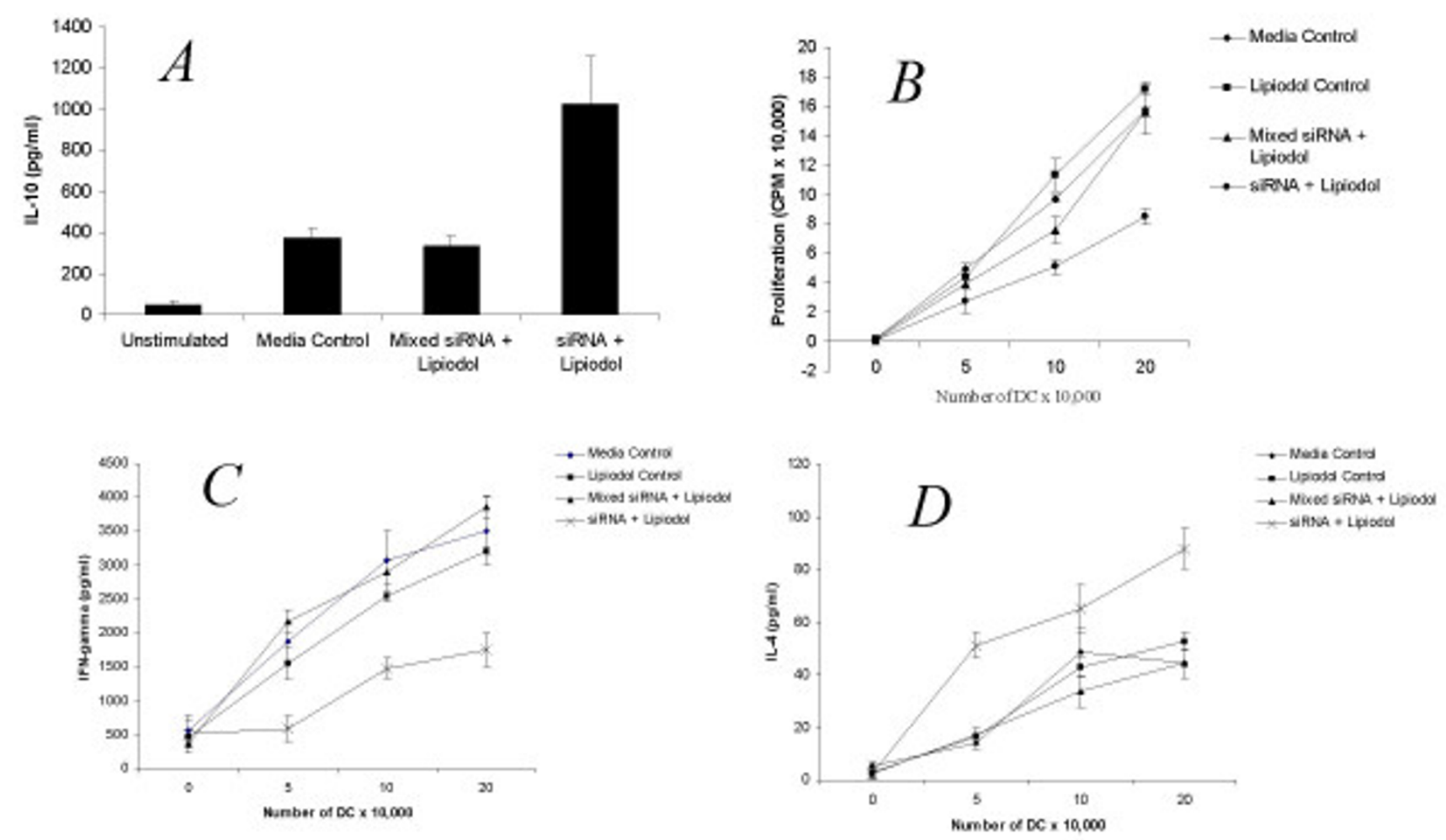

Figure 2

Lipiodol transfected DC are immune modulatory. A. Day 7 bone marrow derived DC were cultured alone or transfected with mismatched siRNA, or IL-I2p35-specific siRNA using $3 \mu \mathrm{l} /$ culture lipiodol. Following a 24 hour incubation cells were plated at $1 \times 10^{6}$ in 6 well culture dishes and activated for 24 hours with $10 \mathrm{ng} / \mathrm{ml}$ LPS and $10 \mathrm{ng} / \mathrm{ml}$ TNF- $\alpha$. Supernatant was harvested and analyzed by ELISA for IL- 10 production. B. C57/BL6 DC were transfected with mismatched siRNA, IL-I2p35-specific siRNA or lipiodol alone, irradiated (3,000 rad) and seeded in triplicate at various concentrations in a flat-bottom 96 -well plate. Splenic T cells from BALB/c mice were added as responders $\left(5 \times 10^{5}\right.$ cells/well). The mixed lymphocytes were cultured for 72 $\mathrm{h}$ and proliferation was assessed by thymidine incorporation. $C \& D$. IFN- $\gamma$ and IL- 4 concentrations, respectively, were assessed from MLR cultures at 48 hours of incubation.

method of inducing activation of bone marrow derived DC for production of IL-12, as well as upregulation of costimulatory molecules such as CD40, CD80 and CD86 [27]. Using this stimulation system, and assessing IL-12 p70 production by ELISA, we sought to determine the potency of mixed lipiodol with siRNA to p35 at suppressing IL-12 production. We administered naked siRNA, and siRNA in various concentrations of lipiodol to day-7 bone marrow derived C57/BL6 DC. Activation by LPS/TNF was performed on day 8 while culture supernatants were assessed for IL-12 production on day 10 of culture. We observed that siRNA transfection with GenePorter induced a potent ( $>90 \%$ ) inhibition of IL-12 production and that the naked siRNA induced a smaller (>30\%) inhi- bition. Transfecting the siRNA with lipiodiol at concentration of 2 and $3 \mu \mathrm{l} /$ well induced a significantly stronger inhibition of IL-12 production $(>75 \%)$ as compared to naked siRNA, but not to the same extent as GenePorter (Figure 1). Similarly to our previously published experiments, administration of mismatched siRNA had no inhibitory effect on production of IL-12 (data not shown). Furthermore, although it has previously been reported that lipiodol is not cytotoxic even at high concentrations [28], we wanted to discount the possibility that lipiodol was mediated non-specific killing of DC. Viability assays using annexin-V and PI staining and analyzed by flow cytometry demonstrated no increase in apoptosis or necrosis in comparison to untreated DC (data not 

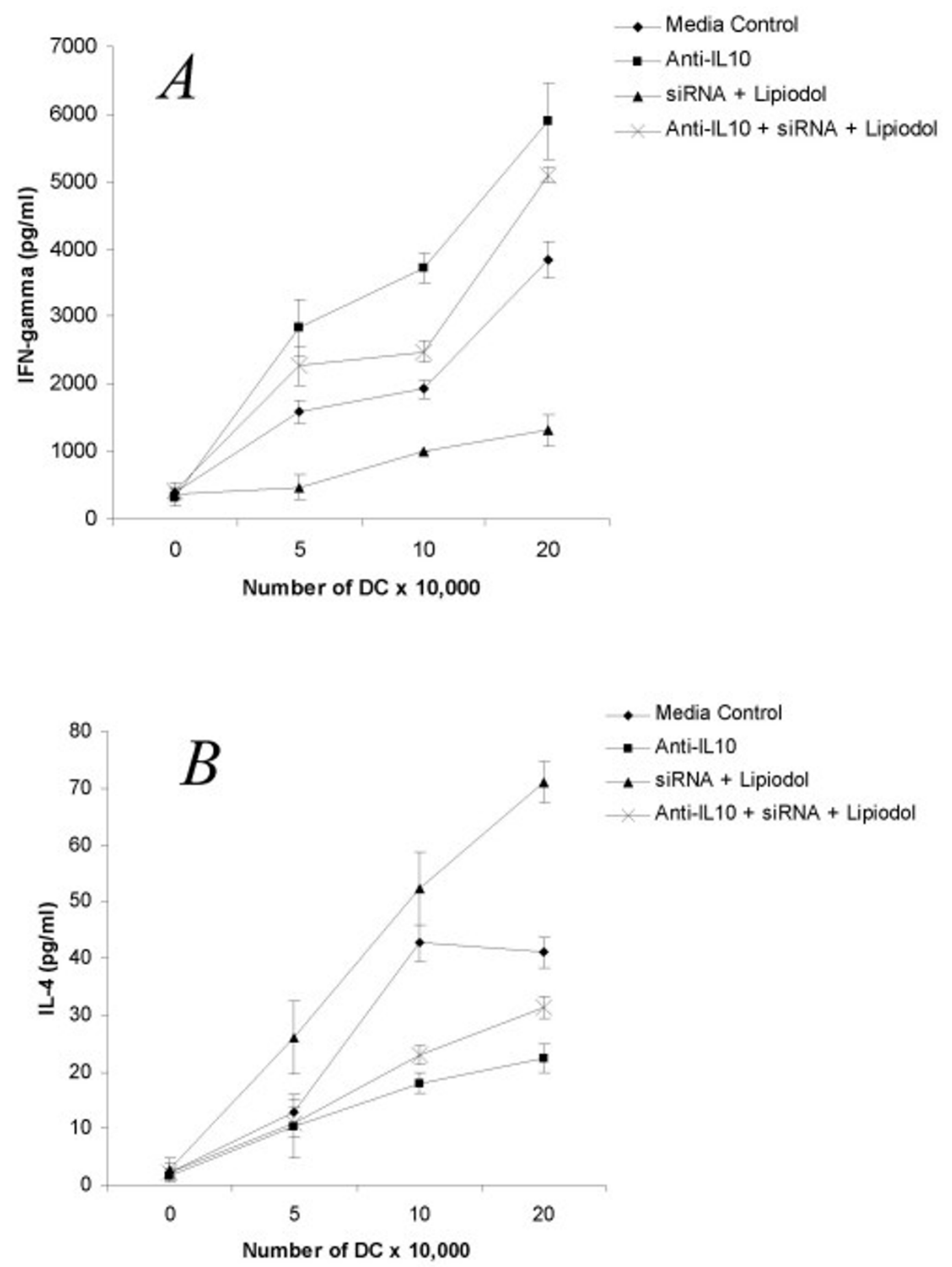

Figure 3

IL- I 0 is mediates immune modulation by IL-I 2 silenced DC. A. MLR was performed with various concentrations of irradiated C57/BL6 stimulator DC transfected with siRNA to IL- I2p35 or control transfected DC, and BALB/c responder T cells. $5 \mu \mathrm{l} / \mathrm{ml}$ of anti-IL-I0 (JES5 2A5) antibody was added throughout the culture time. Supernatant was collected from 48-hour MLR cultures and assessed for IFN- $\gamma$ or IL-4 (B) by ELISA. 

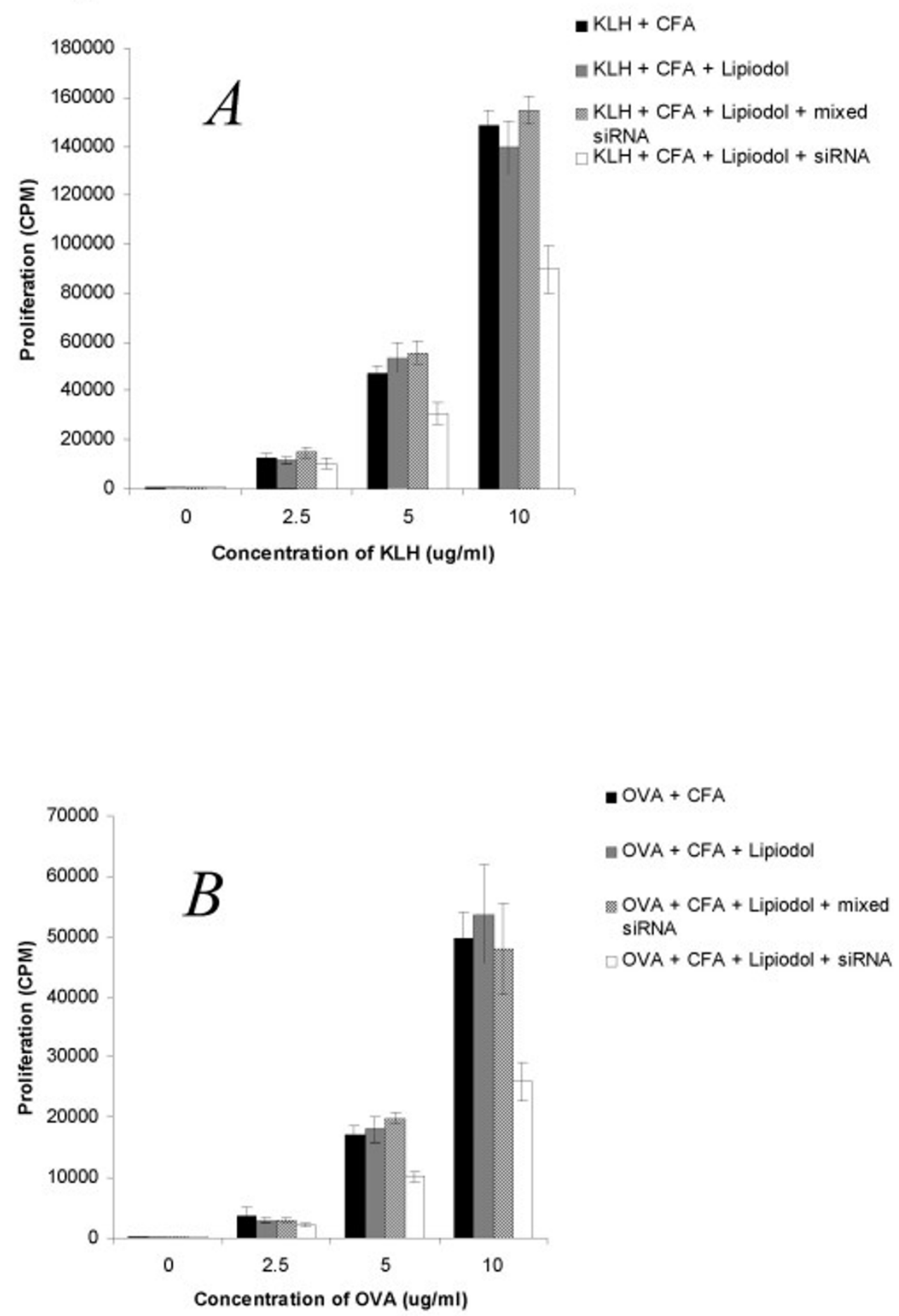

\section{Figure 4}

Inhibition of recall response by lipiodol/siRNA vaccine. A. C57/BL6 mice were immunized intradermally at the interior side of both hind legs with $100 \mu \mathrm{l}$ of KLH or ovalbumin $(1 \mu \mathrm{g} / \mu \mathrm{l})$ emulsified in CFA in the presence or absence of $10 \mathrm{nMol}$ siRNA and $10 \%$ lipiodol. After 14 days mice were sacrificed and $T$ cell recall responses were assessed culturing purified CD4+ T cells with irradiated syngeneic splenocytes in triplicate and mixed with serial dilutions of KLH or OVA (B) at concentrations ranging from $0-10 \mathrm{ug} / \mathrm{ml}$. Following a 72-h incubation, proliferation was assessed by thymidine incorporation. 
Table I

\begin{tabular}{lccc}
\hline & CD80 & Surface molecules (MFI) & CD86 \\
& & & \\
Unactivated DC & & & \\
Media Control & $571.7( \pm 23)$ & $1194( \pm 125)$ & $29.5( \pm 1.5)$ \\
Lipiodol Control & $567.3( \pm 21)$ & $1251( \pm 173)$ & $28.6( \pm 1.3)$ \\
Mixed siRNA & $572.5( \pm 10)$ & $1365( \pm 157)$ & $29.7( \pm 1.3)$ \\
siRNA alone & $559.6( \pm 33)$ & $1201( \pm 193)$ & $30.1( \pm 0.9)$ \\
siRNA + Lipiodol & $577.3( \pm 15)$ & $1195( \pm 103)$ & $30.4( \pm 1.3)$ \\
Post-MLR & $1962.9( \pm 136)$ & $2707.1( \pm 576)$ & $140.5( \pm 35.4)$ \\
Lipiodol Control & $1933.2( \pm 324)$ & $3031.6( \pm 489)$ & $170.3( \pm 26.9)$ \\
Mixed siRNA & $1905.7( \pm 351)$ & $2759.9( \pm 392)$ & $167.2( \pm 46.9)$ \\
siRNA alone & $2050.8( \pm 119)$ & $3051.1( \pm 335)$ & $153.3( \pm 36.7)$ \\
siRNA + Lipiodol & & & \\
Post-MLR + Anti-ILI0 & $3529( \pm 302)$ & $4862( \pm 583)$ & $236.0( \pm 47.3)$ \\
Lipiodol Control & $3442( \pm 247)$ & $4777( \pm 773)$ & $242.8( \pm 58.9)$ \\
Mixed siRNA & $3723( \pm 453)$ & $4863( \pm 669)$ & $237.4( \pm 43.5)$ \\
siRNA alone & $3985( \pm 339)$ & $4957( \pm 501)$ & $254.3( \pm 49.3)$ \\
siRNA + Lipiodol & & & \\
\hline
\end{tabular}

Surface staining for FACS analysis was performed using anti-CDI Ic Ab (gated DC) and anti-CD80, CD86 or CD40 Abs (MFI values). Samples stained with the appropriate isotype-matched control Abs were analyzed in parallel to establish the gating criterion. Results are representative of at least three independent experiments for each culture condition.

shown). Overall, these data support the notion that lipiodol is an easy to use method of transfecting bone marrow derived DC in vitro DC.

\section{Immune modulation by lipiodol/siRNA}

We have previously demonstrated that DC silenced for the IL-12p35 subunit possess an increased production of IL10 and are poor stimulators of MLR [19]. Using the $3 \mathrm{ul}$ concentration of lipiodol that we found most effective at inhibiting IL-12 production in Fig 1, we verified whether the lipiodol/siRNA treated DC possessed the same immunomodulatory properties as previously reported by us. Indeed, we observed that siRNA transfected by lipiodol induced a specific increase in IL-10 production by LPS/ TNF stimulated DC as seen in Fig 2a. Since the specific function of DC in vivo is stimulation of T cell responses, we sought to determine whether the siRNA/lipiodol mixture had effects on inhibition of mixed lymphocyte reaction (MLR). Indeed, the siRNA specific for IL-12 p35 and not the mismatched (mixed) control inhibited proliferation of responding T cells in a 3 day MLR with naïve BALB/ c splenocytes. Furthermore, as seen in Fig $2 b$ the lipiodol alone did not suppress allostimulatory ability of the DC, indicating that the siRNA itself was specifically inducing inhibition. When supernatants of the MLR were assayed for the prototypic Th1 and Th2 cytokines IFN- $\gamma$ and IL-4, respectively, an inhibition of IFN- $\gamma$ Fig $2 c$, and upregulation of IL-4 Fig $2 \mathrm{~d}$ was observed. This data is in agreement with our previous work in which we demonstrated Th 1 to Th2 immune modulation by silencing of the IL-12 p35 subunit [19]. Furthermore, the current data supports the use of lipiodol as a transfection reagent for induction of immune modulation by siRNA.

\section{ThI > Th2 shift is associated with IL-10 production}

In our previous studies we have observed that silencing IL12 is associated with an upregulation in IL-10 production [19]. While IL-10 has previously been described to be a Th2 cytokine [29], it has recently been implicated in generation of $\mathrm{CD} 4^{+} \mathrm{CD} 25^{+} \mathrm{T}$ regulatory cells [30] and TR1 cells [31]. We wanted to assess whether siRNA silencing mediated immune modulation is associated with autocrine IL-10 production by the DC. Indeed, it is known that immature and tolerogenic DC produce this cytokine in an autocrine fashion [32] and that gene-silencing of IL-10 on DC stimulates Th1 immunity and DC maturation [18]. With this in mind we added blocking anti-IL-10 antibodies to siRNA treated DC during stimulation of allogeneic BALB/c T cells in MLR. A dose-dependent inhibition in ability to stimulate Th1 responses was seen with addition of anti-IL-10. Specifically, the IL-12 silenced DC stimulated the responding T cells to decrease production of IFN$\gamma$ and increase production of IL- 4 as depicted in Fig $3 a$ and $3 \mathrm{~b}$ respectively. Noteworthy is the observation that complete inhibition of Th1 stimulation was not achieved by anti-IL-10, implying that stimulation of IFN- $\gamma$ and inhibition of IL-4 was not completely dependent stimulation of IL-10 and was due to other factors such as suppression of IL-12. Addition of isotype control antibody did not influence cytokine production or proliferation (data not shown). 

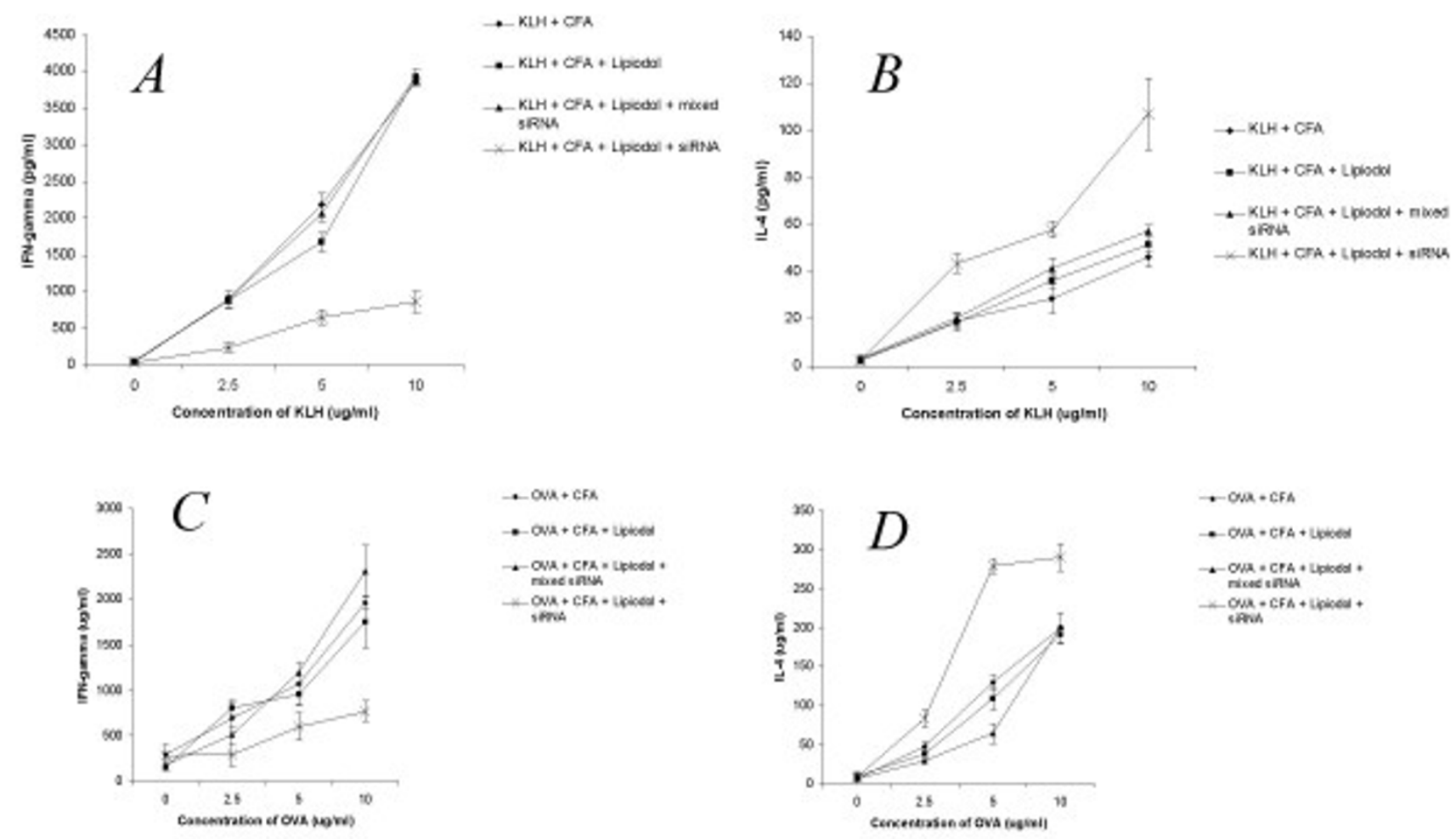

\section{Figure 5}

In vivo immune modulation lipiodol/siRNA vaccine. C57/BL6 mice were immunized intradermally at the interior side of both hind legs with $100 \mu \mathrm{l}$ of $\mathrm{KLH}$ or ovalbumin $(\mathrm{I} \mu \mathrm{g} / \mu \mathrm{l})$ emulsified in CFA in the presence or absence of $10 \mathrm{nMol}$ siRNA and I0\% lipiodol. After 14 days mice were sacrificed and T cell cytokine responses were assessed culturing purified CD4+ T cells with irradiated syngeneic splenocytes in triplicate and mixed with serial dilutions of antigen. IFN- $\gamma$ in KLH (A) and ovalbumin (C) cultures, and IL-4 in KLH (B) and ovalbumin (D) cultures was assessed by ELISA.

While we previously demonstrated that IL-12 silenced DC possessed similar levels of costimulatory molecules as wild-type DC [19], we did not assess whether differences were present after stimulation of DC during the MLR process. This would be anticipated since activated T cells produce a variety of membrane bound (CD40L, CD134L), and soluble factors (IFN- $\gamma$, TRANCE) that stimulate DC maturation [33-37]. Extracting DC using magnetic activated cell sorting (MACS) after the MLR demonstrated significant increases in the mean fluorescent intensity of CD40, CD80 and CD86, however no difference was observed between IL-12 silenced or non-silenced DC. As seen in Table 1, it does not appear that IL-12 silencing leads to Th1>Th2 due to alternation in costimulatory molecule expression. This is particularly interesting since it is known that IL-10 suppresses CD40, CD80, and CD86 expression on DC [38]. Indeed, addition of anti-IL-10 antibody to the MLR significantly increased expression of all 3 costimulatory molecules Table 1 . This is in agree- ment with higher expression of CD40, CD80, and CD86 in IL-10 knockout DC during the process of MLR stimulation as compared with wild-type DC [39].

\section{Lipiodol/siRNA induces Th1>Th2 shift in vivo}

Having demonstrated above that lipiodol can serve as a transfection reagent for uptake of siRNA in DC, combined with the fact that lipiodol is commonly used for a variety of clinical applications $[40,41]$, we assessed whether lipiodol/siRNA can be used to modulate immune responses in vivo. Accordingly, we used the KLH and OVA recall responses as an indicator. C57BL/ 6 mice were immunized with the IL-12 siRNA/lipiodol mixture combined with CFA and either KLH or OVA. 14 days following immunization, recall response experiments were performed using isolated CD4 T cells from draining lymph nodes as previously performed by us [19]. Proliferative responses for both antigens were significantly inhibited in the lipiodol/ siRNA treated animals at restimulation concentrations of 
5 and $10 \mathrm{ug} / \mathrm{ml}$ (Fig $4 \mathrm{a}$ and $4 \mathrm{~b}$ ). When supernatants were harvested and analyzed by ELISA for cytokine response, a Th1 1 Th2 shift was observed for both KLH and ovalbumin as demonstrated by higher production of IFN- $\gamma$ (Fig 5 a and 5c) and IL-4 (Fig 5b and 5d), respectively. In order to assess for antigen specificity, in some experiments, mice were immunized with siRNA/lipiodol with KLH and concurrently injected with mixed siRNA/lipiodol and OVA. The recall response to KLH was suppressed in terms of proliferation and possessed a Th2 cytokine profile, whereas the response to OVA was not immune modulated (data not shown). Other experiments not shown included the immunization in absence of lipiodol which did not result in any immunomodulatory effect of siRNA. Overall, these experiments strongly suggest that siRNA can be administered both in vitro and in vivo for immune modulatory purposes using lipiodol as a carrier.

\section{Discussion}

Lipiodol (trade name Ultra-Fluide ${ }^{\mathrm{TM}}$ ) is an iodized poppy seed oil fatty acid ethylester commonly used as contrast media for radiography [42]. Commonly, lipiodol alone or with chemotherapy is administered to patients with hepatic cell carcinoma for embolization of tumor-feeding arteries, as well as localized delivery of chemotherapy [43]. The finding that lipiodol selectively is uptaken by endothelial cells through pinocytosis [28], combined with the fact that it has previously been used for siRNA delivery in vivo [26] stimulated us to question whether lipiodol can be used as a carrier for siRNA. We observed that although lipiodol was not as effective as GenePorter for in vitro transfection and gene silencing, the inhibitory effects where several fold more potent than the administration of naked siRNA.

We therefore continued to seek whether lipiodol transfer of siRNA can still mediate the immune modulatory effects previously reported by us in terms of switching Th 1 to Th 2 responses [24]. Although this was the case, we also observed that the switch was dependent on IL-10 production. This is somewhat interesting since although IL-10 is a Th2 cytokine, secretion of IL-10 has also been demonstrated to stimulate CD8 proliferation [44], and even to suppress atopy [45], a manifestation of classical Th2 responses. In this study our data supports a prototypic role of IL-10 secreted by DC in stimulation of IL- 4 and IFN- $\gamma$ production. We are however aware that assessment of other Th1/Th2 associated factors are needed to conclusively demonstrate a Th2 switch was occurring. Additionally, although in our hands, similar culture situations stimulate IL-10 production primarily by DC, we can not rule out the production of IL-10 by T cells. Future studies involve looking at $\mathrm{T}$ cell transcription factors such as T-bet and GATA-3, associated with Th1 and Th2 cells, respectively [46].
While we were able to induce in vivo immune modulation through administration of the lipiodol/siRNA mixture, we did not demonstrate that in vivo the DC were indeed the culprits for immune modulation. As previously stated, lipiodol in vivo is pinocytosed by endothelial cells [28], and most likely by other cells such as monocytes and macrophages. Indeed both endothelial cells, and macrophages have been demonstrated to possess immune modulatory activity. For example, antigen presentation by unmanipulated endothelium is known to mediate tolerance in various situations $[47,48]$. Indeed we conceived that the lipiodol itself may be inducing immune modulation due to specific targeting of antigen to endothelial presentation, however this was not the case since lipiodol together with antigen, or together with antigen and mixed siRNA did not mediate immune modulation. However, the fact that the endothelial cells themselves are protolerogenic may allow for synergy with the tolerogenic siRNA administered. The involvement of macrophages in the immune modulation witnessed is another possibility. Indeed, macrophages have been reported to acquire an M1/M2 phenotype similar to Th1/ Th2 [49]. Preliminary experiments have indicated refractoriness to IL-12 production after LPS/TNF stimulation of CD11c DC derived from draining lymph nodes 2-3 days after administration of lipiodol/siRNA, however this will be the subject of an upcoming paper.

Regardless of the cellular mechanisms involved, the ability to immune modulate through administration of a "vaccine composition" with siRNA opens a whole world of novel possibilities both therapeutic and experiments. Through alleviating the need for ex vivo cellular processing, simple siRNA based vaccines can be developed for a variety of disease indications where a Th switch is desired. In terms of clinical applicability, the addition of siRNA for embolization of tumors would allow for induction of immune stimulation at the site of tissue necrosis. This would permit induction of immune responses to antigens released during the embolization procedure. Indeed similar approach used by Adema et al has demonstrated successful induction of immunity through tissue damage combined with immune stimulation [50].

In conclusion, we demonstrate that siRNA can be administered through a clinically useful method, thus opening the possibilities of genetic immune modulation without the use of viruses or ex vivo cellular manipulation.

\section{References}

I. Mosmann TR, Cherwinski H, Bond MW, Giedlin MA, Coffman RL: Two types of murine helper $T$ cell clone. I. Definition according to profiles of lymphokine activities and secreted proteins. J Immunol 1986, I 36:2348-2357.

2. Mosmann TR, Coffman RL: THI and TH2 cells: different patterns of lymphokine secretion lead to different functional properties. Annu Rev Immunol I989, 7: I 45-I73. 
3. Singh VK, Mehrotra S, Agarwal SS: The paradigm of ThI and Th2 cytokines: its relevance to autoimmunity and allergy. Immunol Res 1999, 20:147-161.

4. Sospedra M, Martin R: Immunology of Multiple Sclerosis. Annu Rev Immunol 2004.

5. Miossec $\mathrm{P}$, van den Berg W: Th I/Th2 cytokine balance in arthritis. Arthritis Rheum 1997, 40:2105-21I5.

6. Dabbagh K, Lewis DB: Toll-like receptors and T-helper-I/Thelper-2 responses. Curr Opin Infect Dis 2003, 16:199-204.

7. Steinman RM: The control of immunity and tolerance by dendritic cell. Pathol Biol (Paris) 2003, 5 I:59-60.

8. Agrawal S, Agrawal A, Doughty B, Gerwitz A, Blenis J, Van Dyke T, Pulendran B: Cutting edge: different Toll-like receptor agonists instruct dendritic cells to induce distinct Th responses via differential modulation of extracellular signal-regulated kinase-mitogen-activated protein kinase and c-Fos. J Immunol 2003, I 7 I:4984-4989.

9. Redecke V, Hacker H, Datta SK, Fermin A, Pitha PM, Broide DH, Raz $E$ : Cutting edge: activation of Toll-like receptor 2 induces a Th2 immune response and promotes experimental asthma. J Immunol 2004, I 72:2739-2743.

10. Mazzoni A, Segal DM: Controlling the Toll road to dendritic cell polarization. J Leukoc Biol 2004, 75:72I-730.

II. Papaccio G, Nicoletti F, Pisanti FA, Bendtzen K, Galdieri M: Prevention of spontaneous autoimmune diabetes in NOD mice by transferring in vitro antigen-pulsed syngeneic dendritic cells. Endocrinology 2000, I41:1500-1505.

12. Feili-Hariri M, Dong X, Alber SM, Watkins SC, Salter RD, Morel PA: Immunotherapy of NOD mice with bone marrow-derived dendritic cells. Diabetes 1999, 48:2300-2308.

13. Morita Y, Yang J, Gupta R, Shimizu K, Shelden EA, Endres J, Mule J], McDonagh KT, Fox DA: Dendritic cells genetically engineered to express IL-4 inhibit murine collagen-induced arthritis. J Clin Invest 200I, 107: I275-1284.

14. Link H, Huang YM, Masterman T, Xiao BG: Vaccination with autologous dendritic cells: from experimental autoimmune encephalomyelitis to multiple sclerosis. I Neuroimmunol 200I, II 4: I-7.

15. Yang JS, Xu LY, Huang YM, Van Der Meide PH, Link H, Xiao BG Adherent dendritic cells expressing high levels of interleukin- 10 and low levels of interleukin- 12 induce antigen-specific tolerance to experimental autoimmune encephalomyelitis. Immunology 2000, I01:397-403.

16. Tang G: siRNA and miRNA: an insight into RISCs. Trends Biochem Sci 2005, 30:106-1/4.

17. Elbashir SM, Harborth J, Lendeckel W, Yalcin A, Weber K, Tuschl T: Duplexes of 21 -nucleotide RNAs mediate RNA interference in cultured mammalian cells. Nature 200I, 4I I:494-498.

18. Liu G, Ng H, Akasaki Y, Yuan X, Ehtesham M, Yin D, Black KL, Yu JS: Small interference RNA modulation of IL- 10 in human monocyte-derived dendritic cells enhances the ThI response. Eur J Immunol 2004, 34: I680-1687.

19. Hill JA, Ichim TE, Kusznieruk KP, Li M, Huang X, Yan X, Zhong R, Cairns E, Bell DA, Min WP: Immune modulation by silencing IL12 production in dendritic cells using small interfering RNA. J Immunol 2003, I 7I:691-696.

20. Flynn MA, Casey DG, Todryk SM, Mahon BP: Efficient delivery of small interfering RNA for inhibition of IL- 12 p40 expression in vivo. J Inflamm (Lond) 2004, I:4.

21. Lovett-Racke AE, Rocchini AE, Choy J, Northrop SC, Hussain RZ, Ratts RB, Sikder D, Racke MK: Silencing T-bet defines a critical role in the differentiation of autoreactive $T$ lymphocytes. Immunity 2004, 21:719-73I.

22. Kobayashi $T$, Yoshimura A: Keeping DCs awake by putting SOCSI to sleep. Trends Immunol 2005, 26: I77-179.

23. Li M, Qian H, Ichim TE, Ge WW, Popov IA, Rycerz K, Neu J, White $D$, Zhong R, Min WP: Induction of RNA interference in dendritic cells. Immunol Res 2004, 30:215-230.

24. Ichim TE, Li M, Qian H, Popov IA, Rycerz K, Zheng X, White D, Zhong R, Min WP: RNA interference: a potent tool for genespecific therapeutics. Am J Transplant 2004, 4: I227-I 236.

25. Klein C, Bock CT, Wedemeyer H, Wustefeld T, Locarnini S, Dienes HP, Kubicka S, Manns MP, Trautwein C: Inhibition of hepatitis B virus replication in vivo by nucleoside analogues and siRNA. Gastroenterology 2003, 125:9-18.
26. Contreras JL, Vilatoba M, Eckstein C, Bilbao G, Anthony Thompson J, Eckhoff DE: Caspase-8 and caspase-3 small interfering RNA decreases ischemia/reperfusion injury to the liver in mice. Surgery 2004, 136:390-400.

27. Ichim TE, Zhong R, Min WP: Prevention of allograft rejection by in vitro generated tolerogenic dendritic cells. Transpl Immunol 2003, I I:295-306.

28. Bhattacharya S, Dhillon AP, Winslet MC, Davidson BR, Shukla N, Gupta SD, Al-Mufti R, Hobbs KE: Human liver cancer cells and endothelial cells incorporate iodised oil. $\mathrm{Br} J$ Cancer 1996, 73:877-88।.

29. Romagnani S: Th1/Th2 cells. Inflamm Bowel Dis 1999, 5:285-294.

30. Horwitz DA, Zheng SG, Gray JD: The role of the combination of IL-2 and TGF-beta or IL- 10 in the generation and function of CD4+ CD25+ and CD8+ regulatory T cell subsets. J Leukoc Biol 2003, 74:47|-478.

31. Levings MK, Gregori S, Tresoldi E, Cazzaniga S, Bonini C, Roncarolo MG: Differentiation of $\mathrm{Trl}$ cells by immature dendritic cells requires IL-10 but not CD25+CD4+ $\mathbf{T r}$ cells. Blood 2005, 105:1162-1169.

32. Corinti S, Albanesi C, la Sala A, Pastore S, Girolomoni G: Regulatory activity of autocrine IL- 10 on dendritic cell functions. J Immunol 200I, 166:4312-4318

33. Serra P, Amrani A, Yamanouchi J, Han B, Thiessen S, Utsugi T, Verdaguer J, Santamaria $P$ : CD40 ligation releases immature dendritic cells from the control of regulatory CD4+CD25+ T cells. Immunity 2003, 19:877-889.

34. Ohshima $\mathrm{Y}$, Tanaka $\mathrm{Y}$, Tozawa $\mathrm{H}$, Takahashi $\mathrm{Y}$, Maliszewski $\mathrm{C}$, Delespesse G: Expression and function of OX40 ligand on human dendritic cells. J Immunol I997, I 59:3838-3848.

35. Nakahara T, Urabe K, Fukagawa S, Uchi H, Inaba K, Furue M, Moro $Y$ : Engagement of human monocyte-derived dendritic cells into interleukin (IL)- 12 producers by IL-I beta + interferon (IFN)-gamma. Clin Exp Immunol 2005, 139:476-482.

36. Walsh MC, Choi Y: Biology of the TRANCE axis. Cytokine Growth Factor Rev 2003, 14:25|-263.

37. Caux C, Massacrier C, Vanbervliet B, Dubois B, Van Kooten C Durand I, Banchereau J: Activation of human dendritic cells through CD40 cross-linking. J Exp Med 1994, 180:1263-1272.

38. De Smedt T, Van Mechelen M, De Becker G, Urbain J, Leo O, Moser M: Effect of interleukin- 10 on dendritic cell maturation and function. Eur J Immunol 1997, 27: I229-1235.

39. He Q, Moore TT, Eko FO, Lyn D, Ananaba GA, Martin A, Singh S, James L, Stiles J, Black CM, Igietseme JU: Molecular basis for the potency of IL- I 0-deficient dendritic cells as a highly efficient APC system for activating ThI response. J Immunol 2005, I 74:4860-4869.

40. Vogl TJ, Wetter A, Lindemayr S, Zangos S: Treatment of unresectable lung metastases with transpulmonary chemoembolization: preliminary experience. Radiology 2005, 234:917-922.

4I. Di Stefano DR, de Baere T, Denys A, Hakime A, Gorin G, Gillet M, Saric J, Trillaud H, Petit P, Bartoli JM, Elias D, Delpero JR: Preoperative percutaneous portal vein embolization: evaluation of adverse events in 188 patients. Radiology 2005, 234:625-630.

42. Hamm B, Wolf KJ: Contrast material for computed tomography and magnetic resonance imaging of the gastrointestinal tract. Curr Opin Radiol I99I, 3:474-482.

43. Bhattacharya S, Novell JR, Winslet MC, Hobbs KE: lodized oil in the treatment of hepatocellular carcinoma. $\mathrm{Br} J$ Surg 1994, 8I:1563-157I.

44. Rowbottom AW, Lepper MA, Garland RJ, Cox CV, Corley EG: Interleukin-10-induced CD8 cell proliferation. Immunology 1999, 98:80-89.

45. Akdis CA, Blaser K: Role of IL- $\mathbf{I O}$ in allergen-specific immunotherapy and normal response to allergens. Microbes Infect 200I, 3:89I-898.

46. Hwang ES, Szabo SJ, Schwartzberg PL, Glimcher LH: T helper cell fate specified by kinase-mediated interaction of T-bet with GATA-3. Science 2005, 307:430-433.

47. Rothermel AL, Wang Y, Schechner J, Mook-Kanamori B, Aird WC Pober JS, Tellides G, Johnson DR: Endothelial cells present antigens in vivo. $B M C$ Immunol 2004, 5:5.

48. Bourdoulous S, Beraud E, Le Page C, Zamora A, Ferry A, Bernard D, Strosberg AD, Couraud PO: Anergy induction in encephalitogenic $\mathbf{T}$ cells by brain microvessel endothelial cells is inhibited by interleukin-I. Eur J Immunol 1995, 25: I I76-I I83. 
49. Modolell M, Corraliza IM, Link F, Soler G, Eichmann K: Reciprocal regulation of the nitric oxide synthase/arginase balance in mouse bone marrow-derived macrophages by THI and TH2 cytokines. Eur J Immunol 1995, 25: I I0 I-I I 04.

50. den Brok MH, Sutmuller RP, van der Voort R, Bennink EJ, Figdor CG, Ruers TJ, Adema G]: In situ tumor ablation creates an antigen source for the generation of antitumor immunity. Cancer Res 2004, 64:4024-4029.

Publish with Bio Med Central and every scientist can read your work free of charge

"BioMed Central will be the most significant development for disseminating the results of biomedical research in our lifetime. " Sir Paul Nurse, Cancer Research UK

Your research papers will be:

- available free of charge to the entire biomedical community

- peer reviewed and published immediately upon acceptance

- cited in PubMed and archived on PubMed Central

- yours - you keep the copyright

Submit your manuscript here:

http://www.biomedcentral.com/info/publishing_adv.asp
BioMedcentral 